\title{
Klasifikasi Gambar Palmprint Berbasis Multi-Kelas Menggunakan Convolutional Neural Network
}

\author{
Taopik Hidayat ${ }^{1}$, Nurul Khasanah ${ }^{2}$, Daniati Uki Eka Saputri ${ }^{3}$, \\ Umi Khultsum $^{4}$, Risca Lusiana Pratiwi ${ }^{5}$
}

\begin{abstract}
Biometric technology is developing to be the most relevant mechanism in identity identification. The main purpose of an identity management system is to be able to establish a relationship between individuals and their identities when needed under certain conditions. Among the newly proposed identity verification and personal identification technologies, biometrics is rapidly becoming the most relevant mechanism for identity recognition. This study proposes a new biometric recognition method for authentication and personal identification. Palm image recognition based on image processing for authentication and personal identification is proposed, namely competitive coding using the Convolutional Neural Network (CNN) and Local Binary Pattern (LBP) texture extraction with hyperparameter modifications. The dataset used comes from the Birjand University Mobile Palmprint Database (BMPD) which consists of 20 classes with a total of 800 palm images. The research was conducted using a data distribution of $80 \%$ training data and $20 \%$ validation data. The tests carried out resulted in a good accuracy value of the proposed model of $93.3 \%$ for the training process and $90.6 \%$ for the validation process.
\end{abstract}

Keywords: Biomethric, CNN, LBP

Intisari- Teknologi biometrik berkembang menjadi mekanisme paling relevan dalam pengidentifikasi identitas. Tujuan utama dari sistem manajemen identitas adalah untuk dapat membangun hubungan antara individu dan identitas mereka ketika dibutuhkan dalam kondisi tertentu. Di antara verifikasi identitas yang baru diusulkan dan teknologi identifikasi pribadi, biometrik dengan cepat menjadi mekanisme yang paling relevan untuk pengenalan identitas. Penelitian in mengusulkan metode pengenalan biometrik terbaru untuk otentikasi dan identifikasi pribadi. Pengenalan citra telapak tangan berbasis image processing untuk otentikasi dan identifikasi pribadi yang diusulkan yaitu pengkodean kompetitif menggunakan metode Convolutional Neural Network (CNN) dan ekstraksi tekstur Local Binary Pattern (LBP) dengan modifikasi hyperparameter. Dataset yang digunakan berasal dari Birjand University Mobile Palmprint Database(BMPD) yang terdiri dari 20 kelas dengan total 800 citra telapak tangan. Penelitian dilakukan dengan menggunakan distribusi data sebesar $80 \%$ data training dan $20 \%$ data validasi. Pengujian yang dilakukan menghasilkan nilai akurasi yang baik dari model yang diusulkan sebesar $93,3 \%$ untuk proses training dan $90,6 \%$ untuk proses validasi.

Kata Kunci: Biometrik, CNN, LBP

1,2,3,4,5 Universitas Nusa Mandiri; Jl. Jatiwaringin No. 2, Jakarta Timur; e-mail: Itaopik.toi@nusamandiri.ac.id, 2nurul.nuk@nusamandiri.ac.id, ${ }^{3}$ daniati.due@nusamandiri.ac.id, ${ }^{4}$ umikhultsum.ukm@nusamandiri.ac.id,

5risca.ral@nusamandiri.ac.id

\section{PENDAHULUAN}

Dengan kemajuan teknologi, ada berbagai cara yang dapat dilakukan untuk mengidentifikasi individu atau kelompok untuk tujuan tertentu dan dapat dikatakan sebagai cara untuk mengantisipasi kejahatan. Untuk memenuhi kebutuhan tersebut telah diciptakan beberapa metode untuk mengidentifikasi ciri-ciri biometrik seseorang dengan teknologi baru yang berasal dari metode tradisional atau konvensional (Aima \& Sharma, 2019). Tujuan utama dari sistem manajemen identitas adalah untuk dapat membangun hubungan antara individu dan identitas mereka ketika dibutuhkan dalam kondisi tertentu. Selain itu, mekanisme konvensional seperti kata sandi dan token tidak memberikan bukti yang kuat untuk identifikasi identitas seseorang. Akibatnya, semakin jelas bahwa mekanisme konvensional seperti itu tidak cukup untuk memenuhi kebutuhan identifikasi seseorang (Albelwi \& Mahmood, 2017). Di antara verifikasi identitas yang baru diusulkan dan teknologi identifikasi pribadi, biometrik dengan cepat menjadi mekanisme yang paling relevan untuk pengenalan identitas (Arrofiqoh \& Harintaka, 2018).

Terdapat peneliti sebelumnya yang menerapkan sistem klasifikasi citra, diantaranya penelitian yang dilakukan oleh E. N. Arrofiqoh dan H. Harintaka pada klasifikasi citra tumbuhan menggunakan Convolutional Neural Network (CNN) dengan menggunakan 500 citra tumbuhan beresolusi tinggi. Penelitian yang dilakukan menghasilkan akurasi sebesar 82,0\% (Bejiga, Zeggada, Nouffidj, \& Melgani, 2017). Penelitian yang dilakukan oleh J. Kim et. termasuk struktur retina biologis dengan $C N N$ menggunakan dataset CIFAR10, menghasilkan nilai akurasi 90,8\% (Aima \& Sharma, 2019). Penelitian lebih lanjut tentang identifikasi palem oleh A. Hermana et. Al. Penelitian yang dilakukan dengan menggunakan metode k-NN menghasilkan nilai keberhasilan sebesar $86,7 \%$ (Albelwi \& Mahmood, 2017).

Meskipun sudah banyak penelitian sebelumnya yang telah dilakukan, namun masih ada kemungkinan untuk melakukan penelitian baru dengan hasil yang lebih baik. Dalam penelitian ini diusulkan metode pengenalan citra telapak tangan untuk otentikasi dan identifikasi pribadi. Metode yang diusulkan didasarkan pada skema pengkodean kompetitif menggunakan metode Convolutional Neural Network (CNN) dengan ekstraksi tekstur Local Binary Pattern (LBP). Pengujian implementasi metode Convolutional Neural Network (CNN) dengan untuk membedakan citra telapak tangan, kemudian model diuji dengan validasi data. Model yang telah diuji dengan data validasi kemudian diterapkan untuk mengolah data uji. Pengujian dilakukan dengan menggunakan metode kompilasi cross-entropy kategoris yang kemudian diuji 
sehingga menghasilkan nilai akurasi. Tujuan dari penelitian ini adalah untuk mengklasifikasikan citra telapak tangan menggunakan metode Convolutional Neural Network (CNN) dengan dan ekstraksi ciri Local Binary Pattern (LBP). Hasil penelitian ini diharapkan dapat bermanfaat sebagai pendekatan yang membantu dalam menentukan objek yang sulit diinterpretasikan secara visual. Sehingga didapatkan efisiensi dalam klasifikasi citra.

\section{METODE PENELITIAN}

Tahapan penelitian yang dilakukan dalam penelitian ini antara lain:

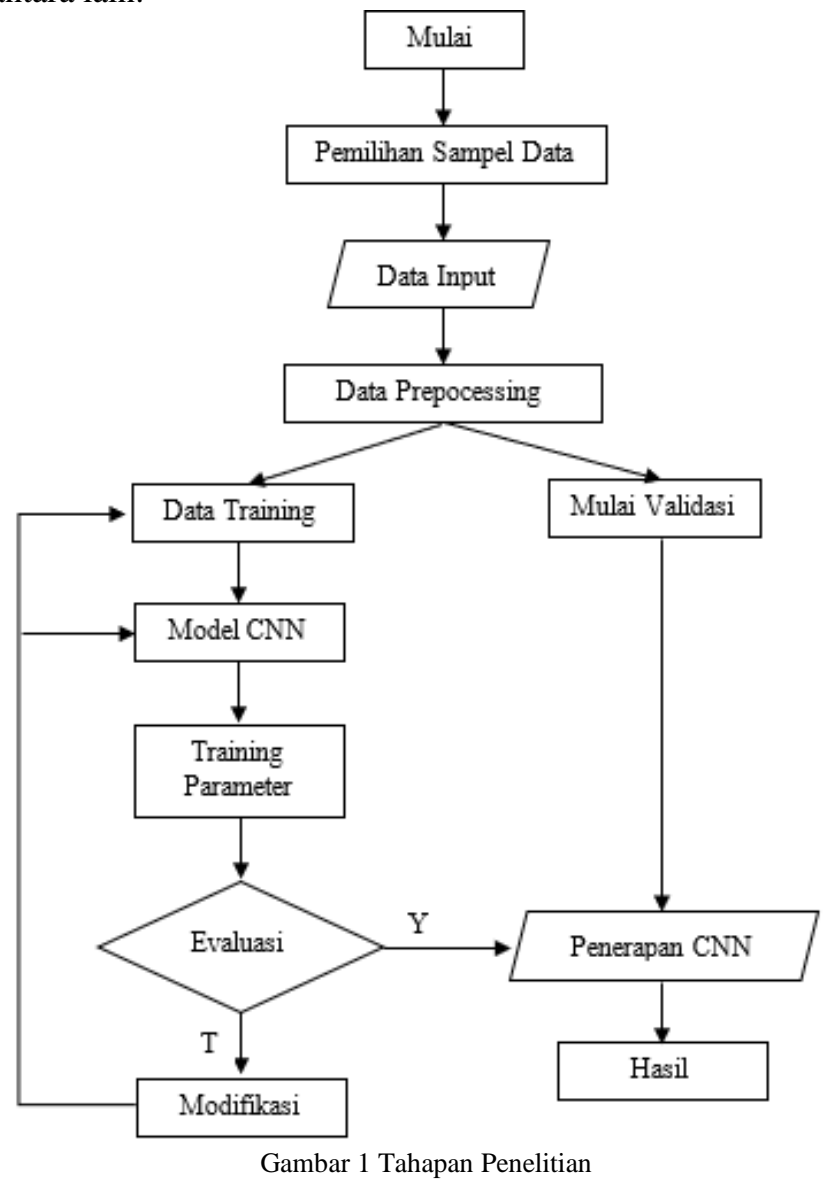

Alur penelitian yang akan digunakan dalam penelitian ini tergambar pada Gambar 1. di atas. Dalam penelitian ini langkah yang dilakukan yaitu tahap pendahuluan, tahap mengumpulkan data dan mengolah data. Pada pendahuluan dimulai dengan menentukan latar belakang masalah, kemudian dilanjutkan dengan tahap pengumpulan dataset citra. Kemudian dari data yang sudah didapatkan dilanjutkan tahap berikutnya yaitu tahap pengolahan data. Pada pengolahan data ini terdapat beberapa tahap diantaranya: menentukan distribusi dataset, menerapkan ekstraksi fitur, melakukan pembentukan dan pelatihan model $C N N$, dan penentuan nilai akurasi dari hasil uji data training dan data validasi.

\section{AKUISISI DATA}

Akuisisi citra dapat didefinisikan sebagai proses menangkap citra dari citra analog menjadi citra digital [7]. Tujuan akuisisi citra adalah untuk menentukan data yang dibutuhkan dan memilih metode perekaman citra digital. Tahap ini dimulai dari objek yang akan digambar (Ghoneim, Muhammad, \& Hossain, 2020). Pada penelitian ini menggunakan citra telapak tangan dari Birjand University Mobile Palmprint Database (BMPD) dengan jumlah 1.640 citra telapak tangan yang terbagi menjadi 41 kelas citra yang mewakili 41 subjek yang berbeda.

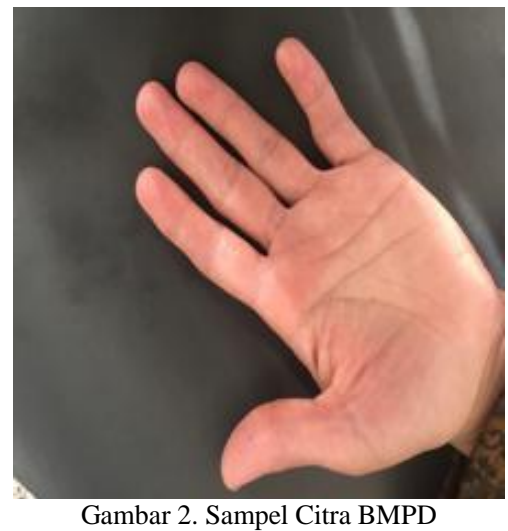

\section{DATA PREPROCESSING}

Pada tahap preprocessing, dilakukan pembagian data menjadi data training dan data validasi. Data training adalah bagian dataset yang kita latih untuk membuat prediksi atau menjalankan fungsi dari sebuah algoritma dan model yang telah dibuat (Hu et al., 2019). Fungsi dari data training adalah untuk memberikan petunjuk melalui algoritma agar sistem yang kita latih bisa mencari korelasinya sendiri atau belajar pola dari data yang diberikan (Mustafa, Halim, Jamlos, \& Idrus, 2020). Sedangkan data validasi adalah bagian dataset yang kita tes untuk melihat keakuratannya, atau dengan kata lain melihat performanya (Hidayatulloh, Herliana, \& Arifin, 2016).

\section{FITUR EKSTRAKSI}

Ekstraksi fitur adalah teknik untuk menggambarkan karakteristik citra dalam set fitur objek terhadap objek yang dimaksud (Satria \& Mushthofa, 2013). Ekstraksi fitur dimaksudkan untuk mendapatkan nilai fitur suatu objek berdasarkan hubungan nilai intensitas piksel suatu citra.

\section{Fitur Ekstraksi Local Binnary Pattern (LBP)}

Local Binary Pattern diperkenalkan pertama kali pada tahun 1992 oleh Timo Ojala dan David Harwood di Universitas Maryland. Local Binary Pattern didefinisikan 
sebagai perbandingan nilai biner piksel pada pusat gambar dengan 8 nilai piksel disekelilingnya (Purwati \& Ariyanto, 2017). Local Binary Pattern merupakan deskriptor untuk mengklarifikasi gambar berdasarkan tekstur gambar. Jadi, sebuah gambar yang berukuran $3 \times 3$, dimana nilai biner pada pusat gambarnya dibandingkan dengan nilai sekelilingnya yang disajikan pada Gambar 3 (Retnoningrum, Widodo, \& Rahman, 2019).

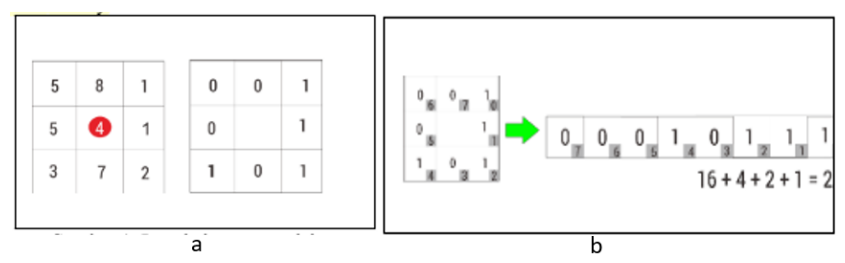

Gambar 3. Langkah pertama dalam Local Binary Pattern (LBP)

\section{Convolutional Neural Network (CNN)}

Convolutional Neural Network (CNN) termasuk dalam jenis deep learning karena kedalaman jaringannya. Deep learning adalah cabang dari machine learning yang dapat mengajarkan komputer untuk melakukan pekerjaan selayaknya manusia (Purwati \& Ariyanto, 2017). Pada CNN setiap neuron dipresentasikan dalam bentuk 2 dimensi, sehingga metode ini cocok untuk pemrosesan dengan input berupa citra (Maggiori, Tarabalka, Charpiat, \& Alliez, 2017).

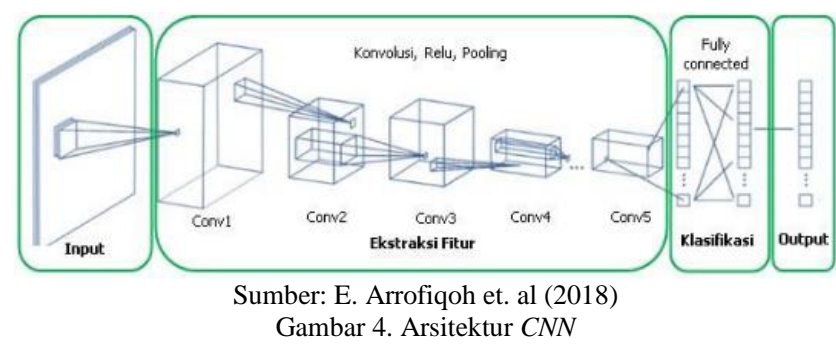

Gambar 4 menggambarkan tentang arsitektur CNN terdiri dari input, proses ekstraksi fitur, proses klasifikasi dan output. Proses ekstraksi dalam $C N N$ terdiri dari beberapa lapisan tersembunyi atau hidden layer, yaitu lapisan konvolusi, fungsi aktivasi $(\operatorname{ReLU})$, dan pooling. CNN bekerja secara hierarki, sehingga output pada lapisan konvolusi pertama digunakan sebagai input pada lapisan konvolusi selanjutnya. Pada proses klasifikasi terdiri dari fully-connected dan fungsi aktivasi (softmax) yang keluarannya berupa hasil klasifikasi (Arrofiqoh \& Harintaka, 2018).

a. Input Layer

Input Layer mewakili citra masukan ke dalam CNN. Anggap citra yang digunakan sebagai masukan berukuran 240x240 piksel dan berjenis RGB (Red, Green, Blue), maka citra input ini berupa array multidimensi dengan ukuran 240x240x3 (3 adalah jumlah channel yaitu merah, hijau dan biru) (M. Raihan Rafiiful Allaam, 2021).

b. Lapisan Konvolusi

Lapisan konvolusi menggunakan filter untuk mengekstraksi objek dari citra input. Filter ini berisi bobot yang digunakan untuk mendeteksi karakter dari objek seperti tepi, kurva, atau warna. Konvolusi akan menghasilkan transformasi linear dari citra input yang sesuai dengan informasi spasial pada data. (Arrofiqoh \& Harintaka, 2018). Ilustrasi proses stride dan padding ditampilkan pada Gambar 5.

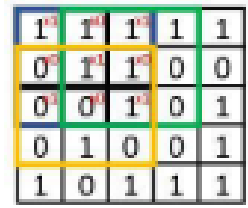

(a)

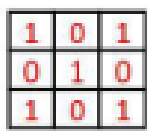

(b)

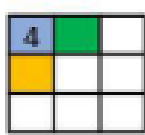

(c)
Gambar 5. Operasi konvolusi dengan stride 1 (a) Input data 5x5 (b) filter $3 \times 3$ (c) bidang receptive $3 \times 3$

c. Fungsi Aktifasi ReLU

ReLU (Rectification Linear Unit) merupakan operasi untuk mengenalkan, nonlinearitas dan meningkatkan representasi dari model (Bewes, Low, Morphett, Pate, \& Henneberg, 2019). Nilai output dari neuron bisa dinyatakan sebagai 0 jika inputnya adalah negatif. Jika nilai input adalah positif, maka output dari neuron adalah nilai input aktivasi itu sendiri (Kim, Sangjun, Kim, \& Lee, 2016).

d. Pooling

Pooling atau subsampling adalah pengurangan ukuran matriks. Terdapat dua macam pooling yang sering digunakan yaitu average pooling dan max pooling (Bejiga et al., 2017). Pooling layer yang sering digunakan yaitu max pooling dan average pooling. Max pooling mengembalikan nilai maksimum dari bagian gambar yang dicakup oleh kernel, sedangkan average pooling mengembalikan nilai rata - rata dari bagian gambar yang dicakup oleh kernel (Alwanda et al., 2020).

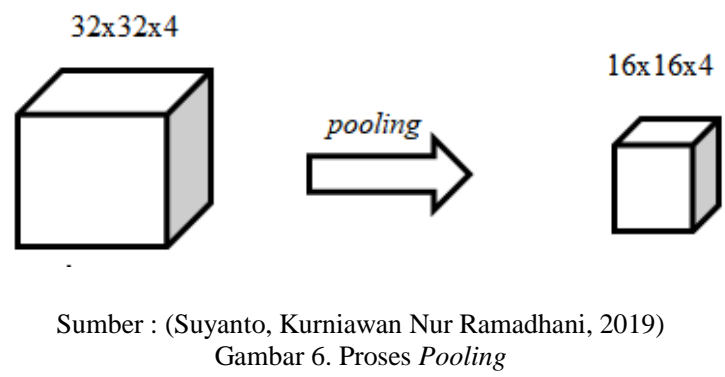


e. ReLU Layer

Aktivasi ReLU (Rectified Linear Unit) merupakan lapisan aktivasi pada model CNN yang mengaplikasikan fungsi $\mathrm{f}(\mathrm{x})=\max (0, \mathrm{x})$ yang berarti fungsi ini melakukan thresholding dengan nilai nol terhadap nilai piksel pada input citra. Aktivasi ini membuat seluruh nilai piksel yang bernilai kurang dari nol pada suatu citra akan dijadikan 0 (Ilahiyah \& Nilogiri, 2018).

\section{f. Fully Connected Layer}

Lapisan fully connected layer merupakan kumpulan dari proses konvolusi (Technology \& Mada, 2020). Lapisan ini mendapatkan input dari proses sebelumnya untuk menentukan fitur mana yang paling berkorelasi dengan kelas tertentu, fungsinya untuk menyatukan semua node menjadi satu dimensi (Albelwi \& Mahmood, 2017).

\section{g. Fungsi Aktivasi Softmax}

Fungsi aktivasi softmax digunakan untuk mendapatkan hasil klasifikasi. Fungsi aktivasi menghasilkan nilai yang diinterpretasi sebagai probabilitas yang belum dinormalisasi untuk tiap kelas. Nilai kelas dihitung dengan menggunakan fungsi softmax (Aima \& Sharma, 2019).

\section{HASIL DAN PEMBAHASAN}

\section{A. AKUiSISI DATA}

Pada penelitian ini data yang digunakan menggunakan data citra publik yang diambil dari Birjand University Mobile Palmprint Database (BMPD) | Kaggle. Data citra yang digunakan oleh peneliti meliputi citra dari 20 kelas dengan setiap kelasnya berjumlah 40 citra telapak tangan dengan jumlah 800 citra. Citra tersebut berasal dari orang yang berbeda dengan ukuran citra $224 \times 224$ piksel, yaitu diberi label 001, 002, sampai dengan 020. Contoh citra dapat dilihat pada Gambar 6. Pembuatan model CNN dilakukan dengan menggunakan Google Collab.

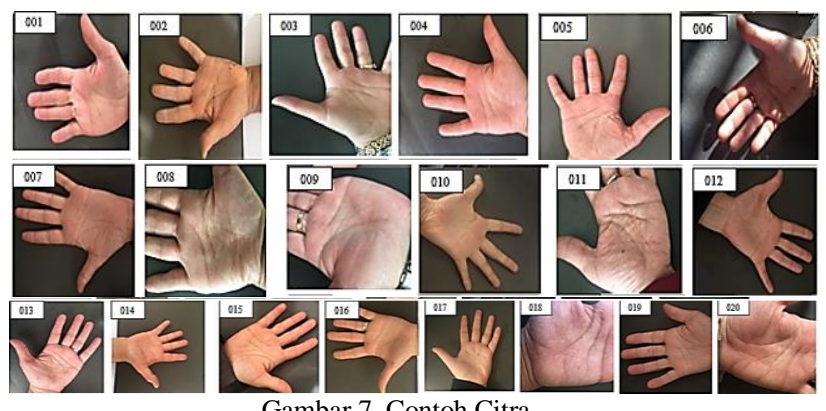

Dari 20 kelas tersebut dibagi menjadi dua jenis kelompok data, yaitu data training dan data validasi. Pembagian kelompok data untuk proses training sebesar $80 \%$, data untuk proses validasi sebesar $20 \%$ dari total keseluruhan data dengan distribusi data pada Tabel 1 .

TABEL I

DISTRIBUSI DATA

\begin{tabular}{llll}
\hline No & Jenis Data & Jumlah Citra & Jenis Data \\
\hline 1 & Data Training & 640 citra & Data Training \\
\hline 2 & Data Validasi & 160 citra & Data Validasi \\
\hline & Total & 800 citra & Total \\
\hline
\end{tabular}

\section{B. Data PREPROCESSING}

Data training yang digunakan adalah $80 \%$ dari total keseluruhan data sehingga didapat data training sebanyak 640 citra dengan dengan pengambilan sampel secara acak. Proses training menggunakan parameter jumlah batch sebanyak 20, dan jumlah epoch sebanyak 50 dan 100. Proses validasi menggunakan data sebanyak $20 \%$ dari total keseluruhan data sehingga didapat data latih sebanyak 160 citra. Proses validasi menggunakan parameter jumlah batch sebanyak 20, dan jumlah epoch sebanyak 50 dan 100.

\section{KLASIFIKASI}

Hasil dari proses training menghasilkan akurasi disajikan pada Tabel 2. Sedangkan hasil dari proses validasi menghasilkan akurasi disajikan pada Tabel 3. Hasil pengujian data training memberikan akurasi yang baik. Grafik akurasi dan loss training disajikan dalam Gambar 7.

TABEL III

HASIL DATA TRAINING

\begin{tabular}{llll}
\hline Model & Epoch & Batch & Akurasi \\
\hline$C N N+L B P$ & 100 & 20 & $93,3 \%$ \\
\hline$C N N+L B P$ & 50 & 20 & $86,9 \%$ \\
\hline \multicolumn{4}{c}{ TABEL IIII } \\
& HASIL DATA VALIDASI \\
\hline Model & Epoch & Batch & Akurasi \\
\hline$C N N+L B P$ & 100 & 20 & $90,6 \%$ \\
\hline$C N N+L B P$ & 50 & 20 & $80,0 \%$ \\
\hline
\end{tabular}

Hasil akurasi yang diperoleh dari data training menggunakan model Convolutional Neural Network (CNN) dengan Linear Binary Pattern (LBP) dengan epoch 100 dan nilai batch size 20 adalah 93.3\%, sedangkan untuk hasil akurasi data validasi menggunakan hyperparameter yang sama yaitu 90,6\%. Hasil akurasi yang diperoleh dari data validasi menggunakan model Convolutional Neural Network (CNN) dengan Linear Binary Pattern (LBP) dengan epoch 100 dan nilai batch size 20 adalah $86.9 \%$, sedangkan untuk hasil akurasi data validasi menggunakan hyperparameter yang sama yaitu $80,0 \%$. 
Berikut adalah grafik akurasi dan nilai loss dari data training dan data validasi. Grafik akurasi dan nilai loss dari data training ditunjukkan pada Gambar 12 dan grafik akurasi dan nilai loss dari data validasi ditunjukkan pada Gambar 13

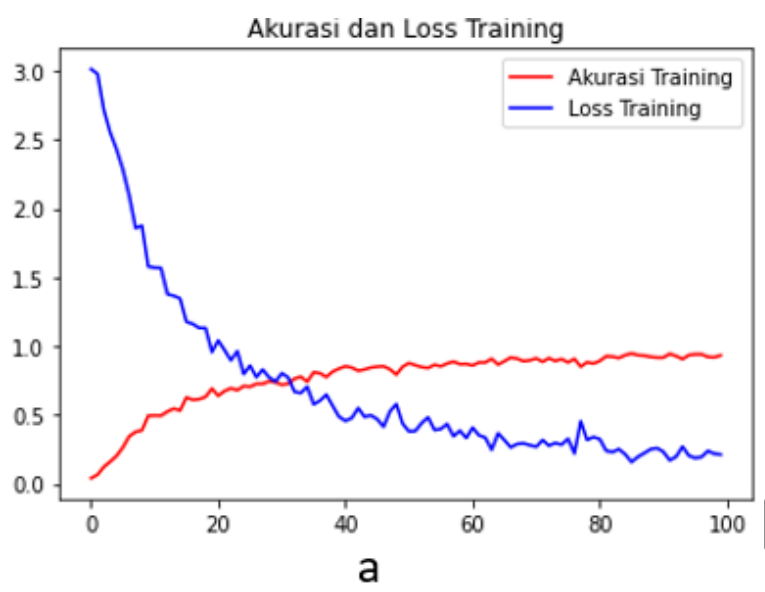

Gambar 8. Grafik akurasi dan loss training

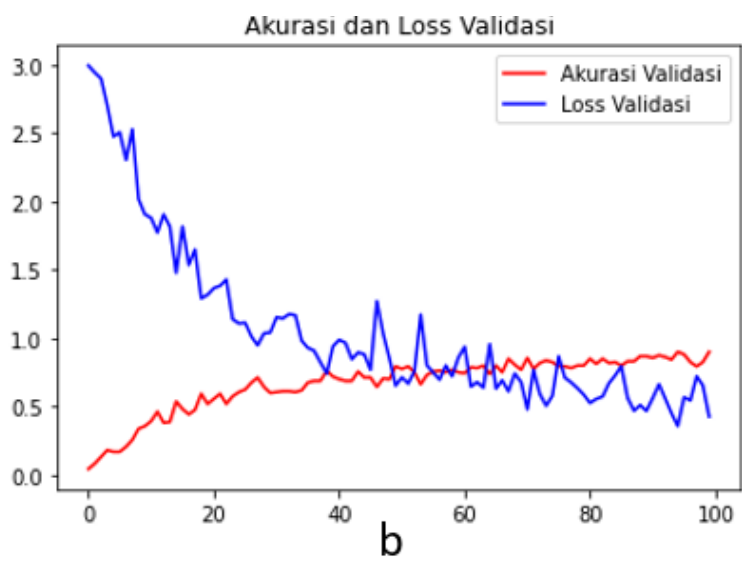

Gambar 9. Grafik akurasi dan loss validasi

\section{KESIMPULAN}

Dari penelitian yang dilakukan dalam klasifikasi citra telapak tangan meggunakan dataset citra telapak tangan dari Birjand University Mobile Palmprint Database (BMPD) menggunakan metode Convolutional Neural Network (CNN) yang telah dimodifikasi, dengan distribusi data $80 \%$ data training dan $20 \%$ data validasi dari total keseluruhan dataset sebanyak 800 citra. Pada metode yang digunakan, dilakukan modifikasi terhadap parameter-parameter dari model yang digunakan yaitu dengan model Convolutional Neural Network $(C N N)$ dan ekstraksi fitur Linear Binary Pattern (LBP) . Jumlah epoch dalam penelitian ini dapat mempengaruhi hasil dari uji data, semakin banyak epoch yang digunakan maka semakin baik nilai akurasi yang didapatkan. Dalam uji data training model yang diusulkan menghasilkan nilai akurasi yang baik, yaitu 93,3\%. Sedangkan untuk uji data validasi menghasilkan nilai akurasi sebesar 90,6\% dengan jumlah epoch 100.

\section{SARAN}

Saran-saran untuk untuk penelitian lebih lanjut untuk menutup kekurangan penelitian ini. Penelitian selanjutnya diharapkan menggunakan tahapan preprocessing dan arsitektur deep learning dengan arsitektur CNN (Convolutional Neural Network) lainnya untuk mendapatkan hasil akurasi yang lebih baik. Selain itu, penelitian selanjutnya ditambahkan rancangan aplikasi untuk penerapan model yang telah dibentuk dalam penelitian sehingga bisa langsung diterapkan oleh tim medis.

\section{REFERENSI}

[1] Aima, A., \& Sharma, A. K. (2019). Predictive Approach for Melanoma Skin Cancer Detection using CNN. SSRN Electronic Journal, 546-552. https://doi.org/10.2139/ssrn.3352407.

[2] Albelwi, S., \& Mahmood, A. (2017). A framework for designing the architectures of deep Convolutional Neural Networks. Entropy, 19(6). https://doi.org/10.3390/e19060242

[3] Alwanda, M. R., Putra, R., Ramadhan, K., Alamsyah, D., Studi, P., \& Informatika, T. (2020). Implementasi Metode Convolutional Neura Network Menggunakan Arsitektur LeNet-5 untuk Pengenalan Doodle. Jurnal Algoritme, 1(1).

[4] Arrofiqoh, E. N., \& Harintaka, H. (2018). Implementasi Metode Convolutional Neural Network Untuk Klasifikasi Tanaman Pada Citra $\begin{array}{llll}\text { Resolusi Tinggi. } & \text { Geomatika, } & \end{array}$ https://doi.org/10.24895/jig.2018.24-2.810

[5] Bejiga, M. B., Zeggada, A., Nouffidj, A., \& Melgani, F. (2017). A convolutional neural network approach for assisting avalanche search and rescue operations with UAV imagery. Remote Sensing, 9(2). https://doi.org/10.3390/rs9020100

[6] Bewes, J., Low, A., Morphett, A., Pate, F. D., \& Henneberg, M. (2019). Artificial intelligence for sex determination of skeletal remains: Application of a deep learning artificial neural network to human skulls. Journal of Forensic and Legal Medicine, 62(July 2018), 40-43. https://doi.org/10.1016/j.jflm.2019.01.004

[7] Aima, A., \& Sharma, A. K. (2019). Predictive Approach for Melanoma Skin Cancer Detection using CNN. SSRN Electronic Journal, 546-552. https://doi.org/10.2139/ssrn.3352407

[8] Albelwi, S., \& Mahmood, A. (2017). A framework for designing the architectures of deep Convolutional Neural Networks. Entropy, 19(6). https://doi.org/10.3390/e19060242

[9] Alwanda, M. R., Putra, R., Ramadhan, K., Alamsyah, D., Studi, P., \& Informatika, T. (2020). Implementasi Metode Convolutional Neural Network Menggunakan Arsitektur LeNet-5 untuk Pengenalan Doodle. Jurnal Algoritme, 1(1).

[10] Arrofiqoh, E. N., \& Harintaka, H. (2018). Implementasi Metode Convolutional Neural Network Untuk Klasifikasi Tanaman Pada Citra Resolusi Tinggi. Geomatika, 24(2), 61 . https://doi.org/10.24895/jig.2018.24-2.810

[11] Bejiga, M. B., Zeggada, A., Nouffidj, A., \& Melgani, F. (2017). A convolutional neural network approach for assisting avalanche search and rescue operations with UAV imagery. Remote Sensing, 9(2). https://doi.org/10.3390/rs9020100

[12] Bewes, J., Low, A., Morphett, A., Pate, F. D., \& Henneberg, M. (2019). Artificial intelligence for sex determination of skeletal remains: Application of a deep learning artificial neural network to human skulls. 
Journal of Forensic and Legal Medicine, 62(July 2018), 40-43 https://doi.org/10.1016/j.jflm.2019.01.004

[13] Ghoneim, A., Muhammad, G., \& Hossain, M. S. (2020). Cervical cancer classification using convolutional neural networks and extreme learning machines. Future Generation Computer Systems, 102, 643649. https://doi.org/10.1016/j.future.2019.09.015

[14] Hidayatulloh, T., Herliana, A., \& Arifin, T. (2016). Klasifikasi Sel Tunggal Pap Smear Berdasarkan Analisis Fitur Berbasis Nä̈ve Bayes Classifier Dan Particle Swarm Optimization. ., 4(2), 186-193.

[15] Hu, L., Bell, D., Antani, S., Xue, Z., Yu, K., Horning, M. P., ... Schiffman, M. (2019). An Observational Study of Deep Learning and Automated Evaluation of Cervical Images for Cancer Screening. Journal of the National Cancer Institute, 111(9), 923-932. https://doi.org/10.1093/jnci/djy225

[16] Ilahiyah, S., \& Nilogiri, A. (2018). Implementasi Deep Learning Pada Identifikasi Jenis Tumbuhan Berdasarkan Citra Daun Menggunakan Convolutional Neural Network. JUSTINDO (Jurnal Sistem Dan Teknologi Informasi Indonesia), 3(2), 49-56.

[17] Kim, J., Sangjun, O., Kim, Y., \& Lee, M. (2016). Convolutional Neural Network with Biologically Inspired Retinal Structure. Procedia Computer Science, $\quad 88, \quad 145-154$ https://doi.org/10.1016/j.procs.2016.07.418

[18] M. Raihan Rafiiful Allaam, A. T. W. (2021). KLASIFIKASI GENUS TANAMAN ANGGREK MENGGUNAKAN METODE CONVOLUTIONAL NEURAL NETWORK ( CNN ). E-Proceeding of Engineering, 8(2), 3147-3179.

[19] Maggiori, E., Tarabalka, Y., Charpiat, G., \& Alliez, P. (2017). Convolutional Neural Networks for Large-Scale Remote-Sensing Image Classification. IEEE Transactions on Geoscience and Remote Sensing, 55(2), 645-657. https://doi.org/10.1109/TGRS.2016.2612821

[20] Mustafa, W. A., Halim, A., Jamlos, M. A., \& Idrus, S. Z. S. (2020). A Review: Pap Smear Analysis Based on Image Processing Approach. Journal of Physics: Conference Series, 1529(2). https://doi.org/10.1088/1742-6596/1529/2/022080

[21] Purwati, R., \& Ariyanto, G. (2017). Pengenalan Wajah Manusia berbasis Algoritma Local Binary Pattern. Emitor: Jurnal Teknik Elektro, 17(2), 29-38. https://doi.org/10.23917/emitor.v17i2.6232

[22] Retnoningrum, D., Widodo, A. W., \& Rahman, M. A. (2019). Ekstraksi Ciri Pada Telapak Tangan Dengan Metode Local Binary Pattern ( LBP ). Jurnal Pengembangan Teknologi Informasi Dan Ilmu Komputer, 3(3), 2611-2618.

[23] Satria, D., \& Mushthofa, M. (2013). Perbandingan Metode Ekstraksi Ciri Histogram dan PCA untuk Mendeteksi Stoma pada Citra Penampang Daun Freycinetia. Jurnal Ilmu Komputer Dan AgriInformatika, 2(1), 20. https://doi.org/10.29244/jika.2.1.20-28

[24] Suyanto, Kurniawan Nur Ramadhani, S. M. (2019). Deep Learning Modernisasi Mchine Learning untuk Big Data. Bandung: Penerbit Informatika.

[25] Technology, I., \& Mada, U. G. (2020). Introduction of Deep Learning for Computer Vision: A brief update on how AI can be used to fight against Copyright ( c ) 2020 - Dr. Sunu Wibirama. (c).

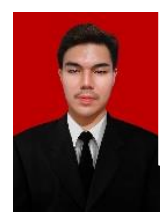

Taopik Hidayat, Tasikmalaya, 31 Desember 1996 Mengajar di Universitas Nusa Mandiri untuk mata kuliah Web Programming dan Mobile Programming.

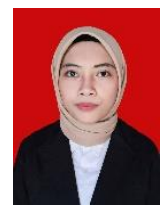

Nurul Khasanah, Kulon Progo, 26 juni 1997. Mengajar : di Universitas Nusa Mandiri untuk mata kuliah Web Programming.

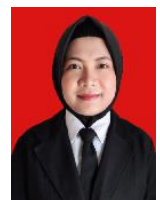

Daniati Uki Eka Saputri, Gunungkidul, 26 Desember 1996. Mengajar : di Universitas Nusa Mandiri untuk mata kuliah Teknik Riset Operasional.

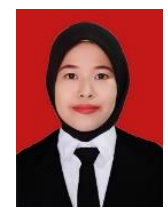

Umi Khultsum, Bantul, 01 November 1996, Mengajar di Universitas Nusa Mandiri untuk mata kuliah Dasar Pemrograman TI.

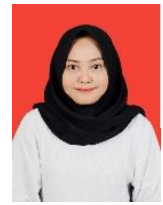

Risca Lusiana Pratiwi, Tangerang, 4 Agustus 1995 , Mengajar di Universitas Nusa Mandiri untuk mata kuliah Metode Perancangan Program. 